ORIGINAL ARTICLE

\title{
BRAF screening as a low-cost effective strategy for simplifying HNPCC genetic testing
}

\author{
E Domingo, P Laiho, M Ollikainen, M Pinto, L Wang, A J French, J Westra, T Frebourg, E Espín, \\ M Armengol, R Hamelin, H Yamamoto, R M W Hofstra, R Seruca, A Lindblom, P Peltomäki, \\ S N Thibodeau, L A Aaltonen, S Schwartz Jr
}

J Med Genet 2004;41:664-668. doi: 10.1136/jmg.2004.020651

See end of article for authors' affiliations

Correspondence to:

Correspondence to:
Dr Simó Schwartz Jr Molecular Oncology and Aging Unit, Centre d'Investigacions en Bioquímica i Biologia Molecular (CIBBIM),

Hospital Universitari Vall d'Hebron, Passeig Vall d'Hebron $119-129$,

Barcelona 08035, Spain;

sschwartz@vhebron.net

Revised version received 19 April 2004

Accepted for publication

20 April 2004

\begin{abstract}
Background: According to the international criteria for hereditary non-polyposis colorectal cancer (HNPCC) diagnostics, cancer patients with a family history or early onset of colorectal tumours showing high microsatellite instability (MSI-H) should receive genetic counselling and be offered testing for germline mutations in DNA repair genes, mainly MLH1 and MSH2. Recently, an oncogenic V600E hotspot mutation within BRAF, a kinase encoding gene from the RAS/RAF/MAPK pathway, has been found to be associated with sporadic MSI-H colon cancer, but its association with HNPCC remains to be further clarified.

Methods: BRAF-V600E mutations were analysed by automatic sequencing in colorectal cancers from 206 sporadic cases with MSI-H and 111 HNPCC cases with known germline mutations in MLH1 and MSH2. In addition, $45 \mathrm{HNPCC}$ cases showing abnormal immunostaining for MSH2 were also analysed.

Results: The BRAF-V600E hotspot mutation was found in $40 \%(82 / 206)$ of the sporadic MSI-H tumours analysed but in none of the 111 tested HNPCC tumours or in the 45 cases showing abnormal MSH2 immunostaining.

Conclusions: Detection of the V600E mutation in a colorectal MSI-H tumour argues against the presence of a germline mutation in either the MLH1 or $\mathrm{MSH} 2$ gene. Therefore, screening of these mismatch repair (MMR) genes can be avoided in cases positive for $\mathrm{V} 600 \mathrm{E}$ if no other significant evidence, such as fulfilment of the strict Amsterdam criteria, suggests MMR associated HNPCC. In this context, mutation analysis of the BRAF hotspot is a reliable, fast, and low cost strategy which simplifies genetic testing for HNPCC.
\end{abstract}

$\mathrm{H}$ ereditary non-polyposis colorectal cancer (HNPCC) is perhaps the most common hereditary colon cancer syndrome, accounting for $3-6 \%$ of the total colorectal cancer burden. ${ }^{1}$ These tumours show a particular molecular phenotype in which thousands of mutations within repetitive sequences accumulate throughout the genome of the tumour cells causing high microsatellite instability (MSI-H). ${ }^{2-5}$ Accumulative data has provided evidence that the underlying event leading to HNPCC is an inherited mutation of a DNA mismatch repair (MMR) gene, mainly MLH1 or MSH2, which account for approximately $90 \%$ of the known mutations to date. ${ }^{67}$ Further, mutations in MSH6 account for almost $10 \%$ of the cases and a small number of mutations in PMS2 have been also reported in a few cases. ${ }^{6-8}$ However, mutations in these four MMR genes account for only half of the HNPCC cases identified by pedigree criteria only. ${ }^{9-11}$ The molecular events causing HNPCC-like pedigrees in which tumours do not have MMR defects is the subject of continued investigation.

The most effective strategy for the diagnosis of HNPCC is the compilation of a thorough family history of colorectal cancer and fulfilment of the Amsterdam criteria. ${ }^{9}$ However, this information is often not available, about $20 \%$ of HNPCC families with germline mutations do not meet these criteria, and further, some colorectal cancer prone families remain mutation negative in MMR gene analyses. ${ }^{11}$ Because microsatellite instability (MSI) is a hallmark of tumours arising in the HNPCC syndrome, ${ }^{34}$ international criteria have been developed to combine clinical and molecular features to help identify those patients at high risk of a diagnosis of HNPCC. ${ }^{11}$ Current recommendations include first testing tumours for the presence of MSI and the absence of protein expression for several of the DNA mismatch repair genes by immunohistochemistry (IHC). Subsequent gene testing can then be targeted to the relevant gene. In this context, available data show that an abnormal immunostaining of MSH2 and MSH6 proteins is most likely the result of germline mutations. When mutations are detected, specific cancer screening and follow up programs are offered to mutation carriers, which have proved profitable in terms of cost-effectiveness when compared to standard care. ${ }^{12-14}$

Up to this point, it has not been considered cost-effective to perform MSI and/or IHC testing of all unselected patients with colorectal cancer. ${ }^{11}$ Most sporadic colorectal tumours show no mismatch repair defects and of the $12-15 \%$ of unselected colorectal tumours that do demonstrate defective MMR, the MSI- $\mathrm{H}^{25}$ phenotype is primarily due to hypermethylation of the MLHl gene promoter, ${ }^{15}{ }^{16}$ and not to germline mutations. Thus, it would be desirable to exclude this latter group from further MMR gene testing. However, the age at onset of colorectal cancer in HNPCC might be older than previously thought and further, some HNPCC patients have minimal family history. ${ }^{17}$ These data suggest that testing of MSI in all colorectal tumours might be considered when population based screenings are performed or whenever possible.

Recently, an oncogenic V600E (previously known as V599E) hotspot mutation in BRAF, a kinase encoding gene from the RAS/RAF/MAPK pathway, has been found in

Abbreviations: HNPCC, hereditary non-polyposis colorectal cancer; $I H C$, immunohistochemistry; MMR, mismatch repair; MSI, microsatellite instability 
colorectal tumours that show MMR deficiency. ${ }^{18-20}$ Further, it has been shown that these mutations occur almost exclusively in tumours located in the proximal colon and with hypermethylation of MLH1, the gene involved in the initial steps of development of these tumours. ${ }^{21}{ }^{22}$ However, in more detailed analyses, BRAF mutations were not detected in those cases with or presumed to have a germline mutation in either MLHl or MSH2. ${ }^{21}{ }^{23}$ Because of these findings, we have further investigated the role of the BRAF mutation V600E in HNPCC cases harbouring known pathogenic mutations in MLH1 or MSH2. Furthermore, we have investigated whether analysis of the V600E mutation might be used as a primary marker to obviate further genetic testing of MLHI and MSH2 in HNPCC diagnostics.

\section{METHODS}

\section{Tumour specimens}

Colon cancers were obtained from the Hospital Universitari Vall d'Hebron (Barcelona, Spain), Groningen University Hospital (Groningen, The Netherlands), Mayo Clinic (Rochester, MN, US), Sapporo Medical University (Sapporo, Japan), Hospital of S. João (Porto, Portugal), Saint-Antoine Hospital (Paris, France), and also from several different hospitals in Finland and Sweden. Sample collection was carried out in accordance with the previously established ethical protocols from each of the participating institutions, and the respective ethics committees approved the study. Collected tumours were either paraffin embedded or immediately frozen in liquid nitrogen for further analyses.

\section{Sporadic colon tumours and MSI analysis}

A total of 206 sporadic colorectal tumours with MSI from the available tumour collections were selected for this study. Genomic DNA was extracted with phenol-chloroform according to standard procedures. Further, tumours were analysed for MSI according to the international criteria for the determination of MSI, using various panels of dinucleotide and mononucleotide repeat sequences. ${ }^{24}{ }^{25}$ All tumours were classified as MSI-H and showed instability in at least $40 \%$ of the micro satellites analysed. ${ }^{24}$ None of them had a family history suggestive of HNPCC.

\section{HNPCC tumour samples and germline mutation analysis of MLH1 and MSH2}

Extensive series of tumours from previously diagnosed HNPCC patients were analysed for germline mutations in the MLH1 and MSH2 genes in each of the institutions involved in this study. DNA was isolated as described above. Analyses were performed using several laboratory routines and mutations verified by automatic sequencing. In some cases, large deletions of MLHI and MSH2 were detected by Southern blotting or alternative strategies. ${ }^{26-28} \mathrm{~A}$ total of 111 HNPCC tumour cases which showed germline mutations of MLH1 or MSH2 were selected for this study. In addition, 45 cases showing abnormal immunostaining for MSH2 were also analysed. Immunohistochemistry for MSH2 was performed as previously described. ${ }^{29}$ Although the germline mutation status of these cases was not determined, current available data strongly suggest that these cases are very likely to contain germline mutations in MSH2. These latter cases were referred for tumour analysis (MSI and IHC) because of either a positive family history or early onset of colon cancer.

\section{Mutational analysis of the BRAF-V600E hotspot}

Analysis of BRAF was performed by automatic sequencing. The fragment encompassing exon 15 was amplified by PCR in all carcinoma samples. Primer sequences and PCR conditions were based on those reported previously. ${ }^{19}$ Genomic DNA (25-100 ng) was amplified by PCR using the following cycling conditions: $30 \mathrm{~s}$ at $94^{\circ} \mathrm{C}, 30 \mathrm{~s}$ at $60^{\circ} \mathrm{C}$, and $45 \mathrm{~s}$ at $72^{\circ} \mathrm{C}$ for 35 cycles. PCR products were purified and sequenced on an ABI Prism 377 Automatic sequencer (Perkin-Elmer, Foster City, CA) using the ABI Prism Dye Terminator Cycle Sequencing Kit (Perkin-Elmer).

\section{RESULTS AND DISCUSSION}

Overall, 77 tumours were obtained from a total of 67 HNPCC families showing 37 different germline mutations in MLHl and 34 tumours accounting for 30 different germline MSH2 mutations were obtained from 33 HNPCC families (table 1). We found the V600E mutation of BRAF in $40 \%(82 / 206)$ of sporadic colon cancer cases showing MSI, which is in agreement with previous reports. ${ }^{19} 20$ However, the V600E mutation was not detected in any of the 111 HNPCC tumours tested nor in any of the 45 additional analysed tumours showing abnormal IHC for MSH2 (table 1), indicating that this hotspot mutation is very rarely if ever involved in the tumourigenesis of colorectal cancer linked to HNPCC $(p<0.001)$. In contrast to the commonly accepted concept that molecular pathways and genes involved in MSI are identical in HNPCC and sporadic colorectal tumours, these results suggest that genotypic differences might distinguish sporadic and hereditary MMR defective colorectal cancers, although the molecular explanation for such a difference is still to be unravelled.

Accordingly, future analysis of the BRAF-V600E mutation as part of the diagnostic protocols for HNPCC is an encouraging perspective. After completion of our study, however, two BRAF mutations have been reported in two mismatch repair deficient colon tumours showing germline alterations in MLHl and MSH2. ${ }^{21}$ Nonetheless, further analyses of these cases showed that the BRAF mutation seen in the MSH2 tumour was a frameshift mutation caused by an insertion of an adenine within a repetitive sequence of five adenines and not V600E. In fact, this mutation generates a truncated protein and is most likely a background mutation of the underlying MMR defect. In addition, as stated by the authors, the alteration detected in the MLHl case was likely to be a non-pathogenic variant. ${ }^{21}$ Furthermore, previous reports have shown that the BRAF-V600E mutation is detected in sporadic colorectal tumours with MSI, but only in those cases characterised by promoter hypermethylation of the MLHl gene, ${ }^{21}{ }^{22}$ suggesting that mechanisms other than inactivation of the mismatch repair system itself might be modulating the tumourigenic advantage capabilities of the V600E mutation. These data are also in agreement with a recent report by Deng et al suggesting that BRAF might be used in a strategy to detect HNPCC families. ${ }^{23}$

Accordingly, our data suggest that if the V600E mutation is detected in a colorectal MSI-H tumour, further testing for germline mutations in MLH1 or MSH2 should be considered only if other significant findings point towards MMR associated HNPCC, such as fulfilment of the strict Amsterdam criteria. Such caution is necessary because colorectal cancer is a common disease and some cases seen in HNPCC families must arise through pathways not involving germline mutations in the MMR pathway. Furthermore, it is not clear yet whether other DNA mismatch repair genes associated with HNPCC, such as hMSH6, will still need to be testing if BRAF-V600E is detected. In this context, the combination of MSI and IHC analyses provides valuable information. Current data suggest that nearly all HNPCC cases involving $\mathrm{MSH} 2$ and MSH6 arise as a consequence of a germline mutation. Thus, identification of these cases by a combination of MSI and IHC is relatively straightforward and highly predictive of a germline alteration. Therefore, germline testing of MSH2 and MSH6 should be considered if IHC demonstrates the involvement of these 


\begin{tabular}{|c|c|c|c|c|c|}
\hline $\begin{array}{l}\text { MLH1 germline alterations } \\
\text { Number of cases }(n=77)\end{array}$ & Families $(n=67)$ & Pathogenic alteration* & $\begin{array}{l}\text { MSH2 germline alterations } \\
\text { Number of cases }(n=79)\end{array}$ & Families $(n=78$ ) & Pathogenic alteration \\
\hline Exon deletions $(n=32)$ & & & Exon deletions $(n=11)$ & & \\
\hline 5 & 5 & Deletion exon 6 & 2 & 2 & Deletion exon 2 \\
\hline 1 & 1 & Deletion exon 11 & 1 & 1 & Deletion exon 8 \\
\hline 19 & 16 & Deletion exon 16 & 1 & 1 & Deletion exon 9 \\
\hline 1 & 1 & Deletion exon 17 & 1 & 1 & Deletion exon 12 \\
\hline 3 & 1 & Deletion exons 1-15 & 1 & 1 & Deletion exons 1-3 \\
\hline 1 & 1 & Deletion exons 1-16 & 1 & 1 & Deletion exons 1-6† \\
\hline 1 & 1 & Deletion exons 4-11 & 1 & 1 & Deletion exons $7-10$ \\
\hline \multirow[t]{3}{*}{1} & 1 & Deletion exons $13-15$ & 1 & 1 & Deletion exons 11-14 \\
\hline & & & 1 & 1 & Deletion exons $12-16$ \\
\hline & & & 1 & 1 & Deletion exons $13-15$ \\
\hline \multicolumn{3}{|l|}{ Missense mutations ( $n=20$ ) } & Missense mutations $(n=1)$ & & \\
\hline 2 & 1 & Met (35) Arg & 1 & 1 & Pro (349) Leu† \\
\hline 5 & 2 & Ser (44) Phe & & & \\
\hline 2 & 2 & Gly (67) Arg & & & \\
\hline 1 & 1 & lle (68) Asn & & & \\
\hline 7 & 7 & Ile (107) Arg & & & \\
\hline 1 & 1 & Thr (117) Met & & & \\
\hline 1 & 1 & $\operatorname{Arg}(217)$ Cys & & & \\
\hline 1 & 1 & Tyr (646) Cyst & & & \\
\hline \multicolumn{3}{|l|}{ Nonsense mutations ( $n=5$ ) } & Nonsense mutations ( $n=9$ ) & & \\
\hline 1 & 1 & Arg (226) Stopt & 1 & 1 & Gln (298) Stop \\
\hline 3 & 2 & Arg (659) Stop & 3 & 2 & Arg (406) Stop \\
\hline \multirow[t]{5}{*}{1} & 1 & Trp (714) Stopt & 1 & 1 & $G \ln (419)$ Stop \\
\hline & & & 1 & 1 & Leu (458) Stop \\
\hline & & & 1 & 1 & Met (621) Stop \\
\hline & & & 1 & 1 & Gly (759) Stop \\
\hline & & & 1 & 1 & Leu (811) Stop \\
\hline Nucleotide deletions $(n=5)$ & & & Nucleotide deletions $(n=7)$ & & \\
\hline 1 & 1 & 63 Deletion G† & 1 & 1 & 67 Deletion G \\
\hline 1 & 1 & 378 Deletion GC & 1 & 1 & 406 Deletion T \\
\hline 1 & 1 & 665 Deletion A & 1 & 1 & 811 Deletion TCTG \\
\hline 1 & 1 & 1852 Deletion AAG† & 1 & 1 & 2113 Deletion G† \\
\hline \multirow[t]{3}{*}{1} & 1 & 2179 Deletion CACA $†$ & 1 & 1 & 2228 Deletion CATT \\
\hline & & & 1 & 1 & 2508 Deletion T \\
\hline & & & 1 & 1 & 2629 Deletion AG \\
\hline Amino acid deletions $(n=2)$ & & & Amino acid deletions $(n=1)$ & & \\
\hline 2 & 2 & Deletion Lys (616) & 1 & 1 & Deletion Asn (596) \\
\hline \multicolumn{2}{|l|}{ Nucleotide insertions $(n=3)$} & & Nucleotide insertions $(n=2)$ & & \\
\hline 1 & 1 & 861 Insertion A & 1 & 1 & 679 Insertion A \\
\hline 1 & 1 & 1490 Insertion C & 1 & 1 & 688 Insertion A \\
\hline 1 & 1 & 2198 Insertion AAAC $†$ & & & \\
\hline \multicolumn{3}{|l|}{ Splice site mutations $(n=10)$} & Splice site mutations $(n=3)$ & & \\
\hline 1 & 1 & IVS8+1 G $\rightarrow$ T & 2 & 2 & IVS5+3 A $\rightarrow$ T§ \\
\hline 2 & 2 & $454-1 \mathrm{G} \rightarrow \mathrm{A}$ & 1 & 1 & $1759+2 \mathrm{~T} \rightarrow \mathrm{A} \dagger$ \\
\hline 1 & 1 & $546-1 \mathrm{G} \rightarrow \mathrm{A} \dagger$ & & & \\
\hline 1 & 1 & $790+1 \mathrm{G} \rightarrow \mathrm{A} t$ & & & \\
\hline 1 & 1 & $790+1 \mathrm{G} \rightarrow \mathrm{T} \dagger$ & & & \\
\hline 1 & 1 & $1668-1 \mathrm{G} \rightarrow \mathrm{T} \dagger$ & & & \\
\hline 1 & 1 & 1989+4 Insertion C $†$ & & & \\
\hline 1 & 1 & $1989+5 \mathrm{G} \rightarrow \mathrm{C} \dagger$ & & & \\
\hline \multirow[t]{3}{*}{1} & 1 & $2103+1 \mathrm{G} \rightarrow \mathrm{T} \dagger$ & & & \\
\hline & & & Abnormal IHC $(n=45) \S$ & & \\
\hline & & & 45 & 45 & No expression \\
\hline
\end{tabular}

genes, regardless of other risk factors (fig 1). On the other hand, because epigenetic inactivation of MLHl is a common event in approximately $12 \%$ of all colon cancers, the predictive value of the absence of protein expression for MLHl determined by IHC is not perfect. Although IHC for MLHl is important for identifying the involvement of this gene, the addition of BRAF testing might provide important predictive information. Therefore, if IHC suggests the involvement of MLH1, then the presence of BRAF-V600E suggests that the defective MMR in the tumour is the result of a somatic alteration.

On the other hand, testing of unselected cohorts of colorectal tumours for MSI is currently not recommended by international criteria. Reyes et $a l^{14}$ have recently shown that germline testing of individuals who meet the Amsterdam criteria only, results in the detection of the fewest gene carriers at the lowest cost, whereas MSI testing of all colorectal patients, although having the highest cost, 


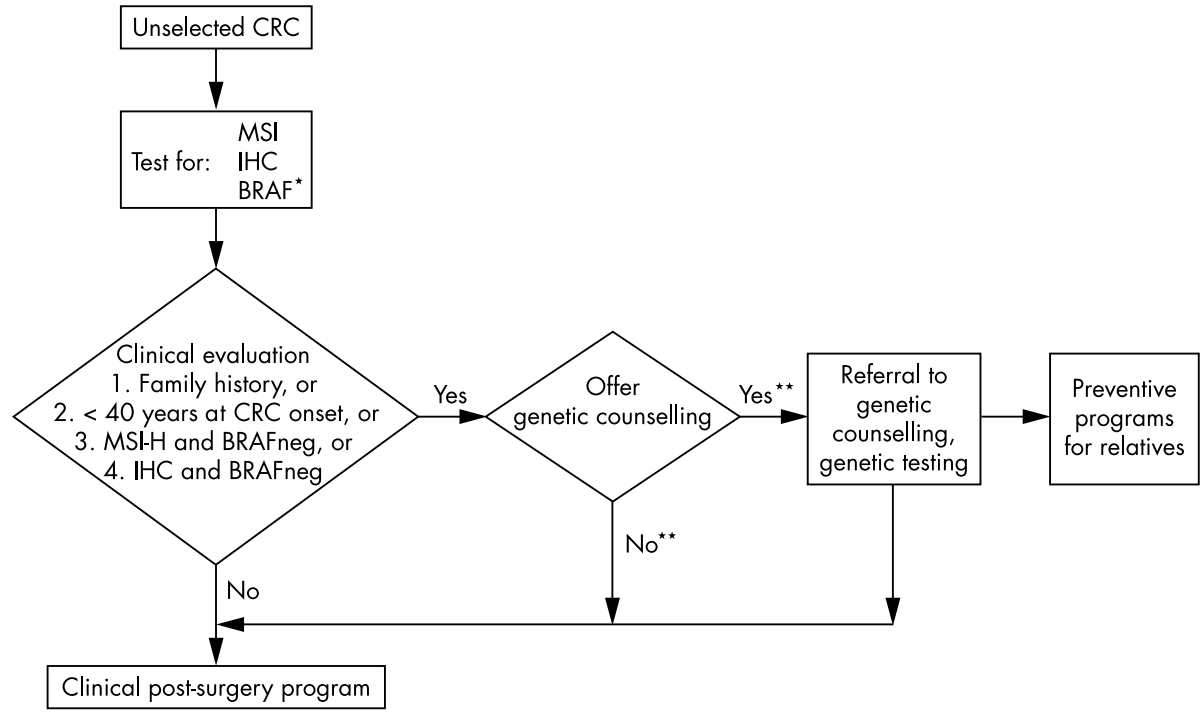

Figure 1 Introduction of BRAF-V600E analysis into testing for germline defects in MLH1 and MSH2 in HNPCC; detection of BRAF-V600E will avoid further testing for germline mutations. The flow chart illustrates the HNPCC diagnostic from unselected cohorts of newly diagnosed tumours analysed for MSI and deems that a positive family history of cancer is always an indication for counselling. ${ }^{* *}$ The diagram also considers whether genetic counselling is accepted or not by the patients when offered. We also suggest that in a population with possible founder mutations, whether BRAF or founder mutation analysis is the first choice test should depend on methodological advantage. IHC: immunohistochemistry analyses of MLH1, MSH2, and $\mathrm{MSH} 6$ are also recommended. *BRAF is analysed only if tumours are $\mathrm{MSI}-\mathrm{H}$ or if $\mathrm{IHC}$ indicates involvement of MLHI. If IHC indicates involvement of $\mathrm{MSH} 2$ or MSH6, analysis of germline mutations of these genes should be the next step. CRC, colorectal cancer.

Table 2 Estimated outcomes from HNPCC testing with and without BRAF-V600E analysis*

Using the Bethesda guidelines

Newly diagnosed cases per year: $129400^{14} 30$

Cases selected for MSI testing: $20833^{14}$

Positive cases showing MSI-H for MMR tests: $2980^{14}$

Newly diagnosed HNPCC cases showing MLH1 or MSH2 alterations: $860^{14}$

Estimated newly diagnosed HNPCC cases showing altered IHC of MSH2: $430 \dagger$

Positive cases showing MSI-H for MMR tests after MSH2 IHC: 2550 (2980-430)

Number of sporadic MSI-H cases: $1260 \ddagger$

Estimated number of BRAF positive cases: $504 \S$

Reduction rate in MMR testing by BRAF analysis: $17 \%(504 / 2980 \times 100)$

Reduction rate in MMR testing by BRAF after MSH2 IHC: $20 \%$ (504/

$2550 \times 100)$ \%

Using unselected cohorts of colorectal tumours

Newly diagnosed cases per year: $129400^{143}$

Positive cases showing MSI-H for MMR tests: 15528

Total newly diagnosed HNPCC cases: 3483

HNPCC cases showing MLH1 or MSH2 alterations: 1747

Estimated newly diagnosed HNPCC cases showing altered IHC of MSH2: 873†

Positive cases showing MSI-H for MMR tests after MSH2 IHC: 14655 (15 528-873)

Number of sporadic MSI-H cases: $12034 \ddagger$

Estimated number of BRAF positive cases: $4813 \S$

Reduction rate in MMR testing by BRAF analysis: $31 \%$ (4813/

$15528 \times 100)$

Reduction rate in MMR testing by BRAF after MSH2 IHC: 33\% (4813/ $14655 \times 10019$

IHC, immunohistochemistry

*Calculations were carried out according to previously published data. ${ }^{14}{ }^{30}$ The number of cases showing MSI-H when using unselected cohorts of tumours is calculated assuming that $12 \%$ of cases will be positive, whereas the total number of HNPCC cases is estimated considering that $2.7 \%$ of total tumours will be HNPCC as reported previously'; †Assuming that half of the newly diagnosed HNPCC cases show altered MSH2 IHC; $¥$ The number of sporadic MSI-H cases has been estimated from the total number of MSI-H cases to be tested for MMR defects and the number of HNPCC cases showing MLHI or MSH2 mutations, assuming that they represent $50 \%$ of the total HNPCC cases; $\S$ The total number of BRAF positive cases has been estimated from our own results, assuming that $40 \%$ of the obtained sporadic MSI-H cases will be positive; $\uparrow$ These cases will not have to be analysed for MSH2. allows the detection of most gene carriers. In this context, application of the Bethesda guidelines (selection of high risk individuals for MSI analysis) represents a mixed strategy in terms of costs and sensitivity for HNPCC diagnostics. Nonetheless, calculations from available data ${ }^{13} 3031$ reveal that the number of candidate patients to be analysed for MSI and MMR genes could be five times higher if unselected cohorts of colorectal tumours are considered (table 2). Also, the number of newly HNPCC diagnosed cases is doubled when unselected cohorts of tumours are used instead of only those meeting the Bethesda guidelines. Further, it has been recently shown that MSI is a predictive factor of tumour response to 5-fluoruracil and irinotecan drug based chemotherapy in colorectal cancer, suggesting a future use of MSI status for directing colorectal cancer patients towards specific and more effective treatments. ${ }^{32} 33$ These data suggest that MSI testing should be considered for all colorectal cancers and question the effectiveness of limiting genetic MSI testing only to individuals who fulfil the Bethesda guidelines, even though the main reason for not applying wide MSI testing strategies is the prohibitive cost. However, when unselected cohorts of tumours are analysed for MSI, family history of cancer must be included in the screening protocols for familial cancer because some colorectal cancer families do not show MSI-H. Therefore, counselling and surveillance has to be offered to those patients with a positive family history even if MSI-H is not detected.

Further, utilisation of the BRAF-V600E mutation status might improve the cost-effectiveness of the actual genetic tests for $\mathrm{HNPCC}^{13}{ }^{14}$ (table 2) and we therefore suggest including BRAF screening as a step prior to germline testing of MLHl in colorectal MSI-H tumours. Further, we also suggest using the same strategy for MSH2 if no immunohistochemistry analysis can be performed previously (fig 1). Accordingly, introduction of the BRAF-V600E test together with IHC analysis of the MMR genes in a decision tree for testing MLHI and MSH2 in these tumours might provide a reliable, fast, and low cost strategy that will help to simplify the current protocols for HNPCC genetic testing. 


\section{Authors' affiliations}

E Domingo, E Espín, M Armengol, S SchwartzJr, Centre d'Investigacions en Bioquímica i Biologia Molecular (CIBBIM), Hospital Universitari Vall d'Hebron, Passeig Vall d'Hebron 119-129, Barcelona 08035, Spain P Laiho, M Ollikainen, P Peltomäki, L A Aaltonen, Department of Medical Genetics, Biomedicum Helsinki, University of Helsinki, 00014 Helsinki, Finland

M Pinto, R Seruca, Instituto de Patologia e Imunologia Molecular da Universidade do Porto (IPATIMUP), 4200-465 Porto, Portugal

L Wang, A J French, S N Thibodeau, Mayo Clinic College of Medicine, Rochester, MN, USA

J Westra, R M W Hofstra, Clinical Genetics Centre, Groningen University Hospital, A. Deusinglaan 4, 9713 AW Groningen, The Netherlands

T Frebourg, Service de Génétique, CHU de Rouen, INSERM EMI-9906, IFRMP Faculté de Médecine et de Pharmacie, 22 Boulevard Gambetta, 76183 Rouen Cedex, France

R Hamelin, INSERM U434 CEPH, 75010 Paris, France

H Yamamoto, First Department of Internal Medicine, Sapporo Medical University, S.1, W.16, Chuo-ku, Sapporo 060-8543, Japan

A Lindblom, Department of Clinical Genetics, Karolinski Hospital, PO Box 60500, S-104 01 Stockholm, Sweden

This work was supported by the Spanish Fondo de Investigaciones Sanitarias (grant number: FIS 01/1350), Spain; the Sigrid Juselius Foundation, European Commission (QLG2-CT-2001-01861); the Finnish Cancer Society, Academy of Finland (44870, Finnish Center of Excellence Program 2000-2005), and Finnish Cultural Foundation Finland; Fundação para a Ciência e a Tecnologia, Portugal (projects: $\mathrm{POCTI} / 35374 / \mathrm{CBO} / 2000$ and POCTI/CBO/40820/2001); the Dutch Cancer Foundation (grant number: 99-1962); and the Swedish Cancer Society.

Conflict of interest: none declared.

\section{REFERENCES}

1 Aaltonen LA, Salovaara R, Kristo P, Canzian F, Hemminki A, Peltomaki P, Chadwick RB, Kaariainen $\mathrm{H}$, Eskelinen $M$, Jarvinen $\mathrm{H}$, Mecklin JP, de la Chapelle A. Incidence of hereditary nonpolyposis colorectal cancer and the feasibility of molecular screening for the disease. N Engl J Med 1998;338: 1481-7.

2 Ionov Y, Peinado MA, Malkhosyan S, Shibata D, Perucho M. Ubiquitous somatic mutations in simple repeated sequences reveal a new mechanism for colonic carcinogenesis. Nature 1993;363:558-61.

3 Aaltonen LA, Peltomaki P, Leach FS, Sistonen P, Pylkkanen L, Mecklin JP, Jarvinen H, Powell SM, Jen J, Hamilton SR. Clues to the pathogenesis of familial colorectal cancer. Science 1993;260:812-6.

4 Peltomaki P, Lothe RA, Aaltonen LA, Pylkkanen L, Nystrom-Lahti M, Seruca R, David L, Holm R, Ryberg D, Haugen A. Microsatellite instability is associated with tumours that characterise the hereditary non-polyposis colorectal carcinoma syndrome. Cancer Res 1993;53:5853-5.

5 Thibodeau SN, Bren G, Schaid D. Microsatellite instability in cancer of the proximal colon. Science 1993;260:816-9

6 Lynch HT, de la Chapelle A. Genetic susceptibility to nonpolyposis colorectal cancer. J Med Genet 1999;36:801-18.

7 Marra G, Boland CR. Hereditary nonpolyposis colorectal cancer: the syndrome, the genes, and historical perspectives. I Natl Cancer Inst 1995;87:1114-25.

8 Miyaki M, Konishi M, Tanaka K, Kikuchi-Yanoshita R, Muraoka M, Yasuno M, Igari T, Koike M, Chiba M, Mori T. Germline mutation of MSH6 as the cause of hereditary nonpolyposis colorectal cancer. Nat Genet 1997;17:271-2.

9 Vasen HFA, Mecklin J-P, Khan PM, Lynch HT. The international collaborative group on hereditary nonpolyposis colorectal cancer (ICG-HNPCC). Dis Colon Rectum 1991:34:424-5.

10 Vasen HFA, Watson P, Mecklin J-P, Lynch HT. New clinical criteria for hereditary nonpolyposis colorectal cancer (HNPCC, Lynch syndrome) proposed by the international collaborative group on HNPCC. Gastroenterology 1999;116:1453-6.

11 Rodriguez-Bigas MA, Boland CR, Hamilton SR, Henson DE, Jass JR, Khan PM Lynch H, Perucho M, Smyrk T, Sobin L, Srivastava S. A National Cancer Institute workshop on hereditary colorectal cancer syndrome: meeting highlights and Bethesda Guidelines. J Natl Cancer Inst 1997;89:1758-62.

12 Nyström-Lahti M, Kristo P, Nicolaides NC, Chang SY, Aaltonen LA, Moisio AL, Jarvinen HJ, Mecklin JP, Kinzler KW, Vogelstein B. Founding mutations and Alu-mediated recombination in hereditary colon cancer. Nat Med 1995; 1:1203-6.

13 Ramsey SD, Clarke L, Tzioni R, Higashi M, Berry K, Urban N. Costeffectiveness of microsatellite screening as a method for detecting hereditary nonpolyposis colorectal cancer. Ann Intern Med 2001;135:577-88.
14 Reyes CM, Allen BA, Terdiman JP, Wilson LS. Comparison of selection strategies for genetic testing of patients with hereditary nonpolyposis colorectal carcinoma: effectiveness and cost-effectiveness. Cancer 2002;95:1848-56.

15 Kane MF, Loda M, Gaida GM, Lipman J, Mishra R, Goldman H, Jessup JM, Kolodner R. Methylation of the hMLH1 promoter correlates with lack of expression of $\mathrm{hMLH1}$ in sporadic colon tumours and mismatch repair defective human tumor cell lines. Cancer Res 1997;57:808-11.

16 Veigl ML, Kasturi L, Olechnowicz J, Ma AH, Lutterbaugh JD, Periyasamy S, Li GM, Drummond J, Modrich PL, Sedwick WD, Markowitz SD. Biallelic inactivation of hMLH1 by epigenetic gene silencing, a novel mechanism causing human MSI cancers. Proc Natl Acad Sci U S A 1998;95:8698-702.

17 Salovaara R, Loukola A, Kristo P, Kaariainen H, Ahtola H, Eskelinen M, Harkonen N, Julkunen R, Kangas E, Ojala S, Tulikoura J, Valkamo E, Jarvinen H, Mecklin JP, Aaltonen LA, de la Chapelle A. Population-based molecular detection of hereditary nonpolyposis colorectal cancer [correction appeared in J Clin Oncol 2000;18:3456]. J Clin Oncol 2000;18:2193-200.

18 Kumar R, Angelini S, Hemminki K. Activating BRAF and N-Ras mutations in sporadic primary melanomas: an inverse association with allelic loss on chromosome 9. Oncogene 2003:22:9217-24.

19 Davies H, Bignell GR, Cox C, Stephens P, Edkins S, Clegg S, Teague J, Woffendin H, Garnett MJ, Bottomley W, Davis N, Dicks E, Ewing R, Floyd Y, Gray K, Hall S, Hawes R, Hughes J, Kosmidou V, Menzies A, Mould C, Parker A, Stevens C, Watt S, Hooper S, Wilson R, Jayatilake H, Gusterson BA, Cooper C, Shipley J, Hargrave D, Pritchard-Jones K, Maitland N, ChenevixTrench G, Riggins GJ, Bigner DD, Palmieri G, Cossu A, Flanagan A, Nicholson A, Ho JWC, Leung SY, Yuen ST, Weber BL, Seigler HF, Darrow TL, Paterson H, Marais R, Marshall CJ, Wooster R, Stratton MR, Futreal PA. Mutations of the BRAF gene in human cancer. Nature 2002:417:949-54

20 Rajagopalan H, Bardelli A, Lengauer C, Kinzler KW, Vogelstein B, Velculescu VE. RAF/RAS oncogenes and mismatch-repair status. Nature 2002;418:934.

21 Wang L, Cunningham JM, Winters JL, Guenther JC, French AJ, Boardman LA, Burgart $\mathrm{L}, \mathrm{McD}$ onnell SK, Schaid DJ, Thibodeau SN. BRAF mutations in colon cancer are not likely attributable to defective DNA mismatch repair. Cancer Res 2003;63:5209-12.

22 Domingo E, Espín E, Armengol M, Oliveira C, Pinto M, Duval A, Brennetot C, Seruca R, Hamelin R, Yamamoto H, Schwartz S Jr. Activated BRAF targets proximal colon tumours with mismatch repair deficiency and $\mathrm{hMLH}$ inactivation. Genes Chromosomes Cancer 2004;39:138-42

23 Deng G, Bell I, Crawley S, Gum J, Terdiman JP, Allen BA, Truta B, Sleisenger MH, Kim YS. BRAF mutation is frequently present in sporadic colorectal cancer with methylated $\mathrm{hMLH} 1$, but not in hereditary nonpolyposis colorectal cancer. Clin Cancer Res 2004;10:191-5.

24 Boland CR, Thibodeau SN, Hamilton SR, Sidransky D, Eshleman JR, Burt RW, Meltzer SJ, Rodriguez-Bigas MA, Fodde R, Ranzani GN, Srivastava SA. A National Cancer Institute workshop on microsatellite instability for cancer detection and familial predisposition: development of international criteria for the determination of microsatellite instability in colorectal cancer. Cancer Res 1998;58:5248-57.

25 Hoang JM, Cottu PH, Thuille B, Salmon RJ, Thomas G, Hamelin R. BAT-26, an indicator of the replication error phenotype in colorectal cancers and cell lines. Cancer Res 1997; 57:300-3.

26 Di Fiore F, Charbonnier F, Martin C, Frerot S, Olschwang S, Wang Q, Boisson C, Buisine MP, Nilbert $M$, Lindblom A, Frebourg T. Screening for genomic rearrangements of the MMR genes must be included in the routine diagnosis of HNPCC. J Med Genet 2004:41:18-20.

27 Gille JJ, Hogervorst FB, Pals G, Wijnen JT, van Schooten RJ, Dommering CJ, Meijer GA, Craanen ME, Nederlof PM, de Jong D, McElgunn CJ, Schouten JP, Menko FH. Genomic deletions of MSH2 and MLH1 in colorectal cancer families detected by a novel mutation detection approach. $\mathrm{Br} J$ Cancer 2002:87:892-7.

28 Wahlberg S, Liu T, Lindblom P, Lindblom A. Various mutation screening techniques in the DNA mismatch repair genes hMSH2 and hMLH1. Genet Test 1999;3:259-64.

29 Cunningham JM, Kim C-Y, Christensen ER, Tester DJ, Parc Y, Burgart L, Halling KC, McDonnell SK, Schaid DJ, Walsh Vockley C, Kubly V, Nelson H, Michels VV, Thibodeau SN. The frequency of hereditary defective mismatch repair in a prospective series of unselected colorectal carcinomas. Am J Hum Genet 2001;69:780-90.

30 American Cancer Society. Cancer facts and figures 1999. Atlanta: American Cancer Society, 1999

31 Vasen HF, Mecklin J-P, Watson P, Utsunomiya J, Bertario L, Lynch $\mathrm{P}$, Svendsen LB, Cristofaro G, Muller H, Meera Khan P, Lynch HT (The International Collaborative Group on HNPCC). Surveillance in hereditary nonpolyposis colorectal cancer: an international cooperative study on 165 families. Dis Colon Rectum 1993;36:1-4.

32 Ribic CM, Sargent DJ, Moore MJ, Thibodeau SN, French AJ, Goldberg RM, Hamilton SR, Laurent-Puig P, Gryfe R, Shepherd LE, Tu D, Redston M, Gallinger S. Tumor microsatellite-instability status as a predictor of benefit from fluorouracil-based adjuvant chemotherapy for colon cancer. N Engl J Med 2003;349:247-57

33 Fallik D, Borrini F, Boige V, Viguier J, Jacob S, Miquel C, Sabourin JC, Ducreux M, Praz F. Microsatellite instability is a predictive factor of the tumor response to irinotecan in patients with advanced colorectal cancer. Cancer Res 2003;63:5738-44 